\title{
Financial Risk Assessment of Listed Companies in Environmental Protection Industry Based on Self- Organizing Neural Network
}

\author{
Hongji Wang ${ }^{1 *}$ \\ School of Finance \\ Guizhou University of Finance and Economics \\ Guiyang, China \\ 1507714060@qq.com
}

\author{
Jianhua $\mathrm{Zhu}^{2}$ \\ School of Finance \\ Guizhou University of Finance and Economics \\ Guiyang, China \\ 948841731@qq.com
}

\begin{abstract}
In China's securities market, the number of companies in financial difficulties is increasing, which has caused very serious losses and consequences for all parties. This paper takes 25 listed companies of environmental protection industry in Shanghai and Shenzhen in $\mathbf{2 0 1 6}$ as research object, and uses selforganizing neural network clustering algorithm to cluster. According to the clustering results, it analyzes and discusses the financial risk issues of various environmental protection companies, and explores new ideas for corporate financial risk research from the perspective of data mining. The empirical results show that the enterprise financial risk research system of self-organizing neural network model has good analytical ability and effective samples classification, and can avoid the disadvantages of $\mathrm{K}$-means method in order to give the number of clusters in advance.
\end{abstract}

Keyword-Listed company; Self-organizing neural network; Environmental protection industry; Financial risk assessment

\section{PUTTING FORWARD QUESTIONS}

In recent years, with the continuous deepening of China's reform and opening up process and the continuous growth and development of China's capital market, the securities market has become an important place for the fund raising and circulation of Chinese enterprises, but the fiercely competitive market environment has caused some listed companies to suffer frequent losses in successive years. In the case of financial operations such as insolvency, the special treatment (ST) and delisting risk warning (*ST) companies emerging from the Shanghai and Shenzhen stock markets have significantly mapped this issue. In China's securities market, the number of companies caught in financial difficulties is increasing, and this has caused very serious losses and consequences for all parties. Effective prevention and control of enterprise financial risks, avoid falling into financial difficulties, for listed companies and many shareholders, even the whole market, has a very important significance.

Corporate financial risk research refers to the analysis and prediction of financial activities of listed companies by means of financial management, statistical analysis, financial accounting, enterprise management and marketing through the use of financial management, statistical analysis, financial accounting, corporate management and marketing. And the future development situation, with a view to discovering the financial risks in the business management activities of enterprises, and making warnings in advance to prevent the financial risks of enterprises from gradually becoming operational risks. At present, the mainstream research methods for analyzing corporate financial risk mainly include fuzzy discriminant method, quantitative analysis method and artificial intelligence algorithm using modern computing technology. Most of the above literatures use quantitative research methods, and the self-organizing neural network clustering algorithm model first clusters enterprises, and then there are few researches on comparative analysis of clustered enterprises. Self-organizing neural network clustering algorithm as a The non-linear prediction model that can automatically obtain sample information, self-organization, self-learning, super memory and good fault tolerance make it uniquely advantageous in the analysis and processing of nonlinear and noisy data. Xu Zhichao (2008) uses the selforganizing mapping neural network, and improves the neighborhood function on this basis, carries on the stock analysis and the choice, has obtained the astonishing satisfactory effect. Liu Aiqin (2017) resides in the SOM neural network clustering algorithm, and uses this algorithm to cluster and optimize the web access behavior of the library of Shanxi University. Xiong Tao (2012) proposed a hybrid model based on self-organizing neural network algorithm and support vector machine (SVM) for multi-step prediction of stock price index. Therefore, this paper classifies the financial risk of enterprises based on self-organizing neural network clustering algorithm, and then compares and analyzes the classification of enterprises, in order to provide a new idea for enterprise financial early warning from the perspective of data mining.

\section{MODEL INTRODUCTION}

Self-Organizing Maps (SOM), which can cluster data by unsupervised learning, is essentially a neural network with only input layer-hidden layer. A node in the hidden layer represents a class that needs to be clustered. Each input sample finds a node in the hidden layer that best matches it, called its active node, also known as "winning neuron". Next, we use random gradient descent method to update the parameters of the activation node. At the same time, the points close to the active node also update the parameters appropriately according to their distance from the active node. One of the characteristics of SOM is that the nodes in the hidden layer are topologically 
related and can discretize the input of any dimension into a one-dimensional or two-dimensional (more unusual) discrete space. The nodes in Computation layer are fully connected to the nodes of Input layer.

The SOM artificial neural network is a characteristic topological distribution that can form an input signal on a onedimensional or two-dimensional array of processing units. The structure is shown in the figure. The network simulates the function of the self-organizing feature map of the human brain neural network. The network consists of an input layer and an output layer. The number of neurons in the input layer is determined according to the number of vectors in the input network. The input neurons are one-dimensional matrices, and the input signals of the network are received, and the output layer is composed of nerves. The elements are arranged into a two-dimensional node matrix in a certain way. The neurons of the input layer and the neurons of the output layer are linked together by weights. When the network receives an external input signal, a certain neuron in the output layer will be excited.

The learning process of SOM network has two modes, one by one random input and batch input, and its algorithm is described as follows:

(1) Each neuron is randomly initialized with a reference weight vector $w_{i}(0)$, given the initial learning rate $\beta_{0}$ and a large enough initial neighborhood size $\sigma_{0}(0)$.

(2) In iterative step T, an input sample is randomly loaded into the network.

(3) Search for winning neurons. The Euclidean distance of the reference weight vector corresponding to the input sample and all neurons is obtained, and the winning neuron is corresponding to the minimum distance.

(4) Update the weights of the winning neurons and other neurons in their neighborhood.

$$
w_{i}(t)=w_{i}(t-1)+\beta_{(t)} N S(d, t)\left[x(t)-w_{i}(t-1)\right]
$$

$$
N S=\operatorname{Exp}\left(\frac{-d_{i, j}^{2}}{2 \sigma^{2}}\right)
$$

In the formula, $w_{i}(t)$ is updated after the $\mathrm{t}$ iteration; $w_{i}(t-1)$ is the update of weights in the previous iteration; $\beta(\mathrm{t})$ is the change of learning rate with the change of iterative $\mathrm{t} ; \mathrm{NS}(\mathrm{d}, \mathrm{t})$ is neighborhood strength, expressed by a function of the distance $d$ from the winner to a neighborhood neuron at the iteration $\mathrm{t} ; \mathrm{X}(\mathrm{t})$ is the input vector represented in the $t$ iteration.

(5) The learning rate function $\beta(t)$ and neighborhood function $\sigma_{T}$ decay with the number of iterations.

(6) Repeat (2) until $\mathrm{t}=t_{\max }$ ( $t_{\max }$ for the maximum number of iterations) ends the clustering process and outputs the result.

\section{THE CONSTRUCTION OF ENTERPRISE FINANCIAL RISK MODEL BASED ON SELF-ORGANIZING NEURAL NETWORK CLUSTERING ALGORITHM}

\section{A. Construction of financial risk indicator system for listed companies}

Financial risk analysis is to analyze and forecast business activities and financial activities, find out potential financial and operational risks, and give warning before the crisis, so as to avoid potential financial and operational risks converting into actual losses.

In order to reflect the financial situation of enterprises more comprehensively, this paper refers to the financial risk index system of Jiaotao (2011), and follows the principles of systematicness, comprehensiveness and dynamics. On the premise that the research data can be obtained, it includes four aspects: operation ability, capital structure, solvency and profitability. 13 specific financial indicators (as shown in Table 1) were selected as the research index system.

TABLE I. INDEX SYSTEM OF ENTERPRISE FINANCIAL RISK

\begin{tabular}{|l|l|l|}
\hline Indicator category & Research indicator name & Index calculation formula \\
\hline \multirow{4}{*}{ Capital structure } & Asset liability ratio & Total debt / total assets \\
\cline { 2 - 3 } & Equity multiplier & Total assets/total shareholders' equity \\
\cline { 2 - 3 } & Liquidity ratio & Liquid assets / total assets \\
\hline \multirow{5}{*}{ Profitability } & Net sales profit & Net profit / sales revenue \\
\cline { 2 - 3 } & Return on net assets & Total operating profit / owner's equity \\
\hline \multirow{5}{*}{ Solvenating capacity } & Inventory turnover & Operating income / annual average stock balance \\
\cline { 2 - 3 } & Accounts receivable turnover rate & Net sales revenue / average balance of accounts receivable \\
\cline { 2 - 3 } & Turnover of current assets & Net principal business income / average total current assets \\
\cline { 2 - 3 } & Turnover of fixed assets & Operating income / net annual average fixed assets \\
\cline { 2 - 3 } & Turnover of total assets & Operating income / annual average total assets \\
\hline & Flow rate & Total current assets / current liabilities \\
\cline { 2 - 3 } & Speed ratio & End of term assets / end current liabilities \\
\cline { 2 - 3 } & Proportion of property rights & Total liabilities / shareholders' equity \\
\hline
\end{tabular}




\section{B. Problems in the Green Financial Legal System sample selection and data sources}

The financial statements of listed companies can reflect the company's financial situation and development trends. This paper selects 25 listed companies of environmental protection in Shanghai and Shenzhen stock markets in 2016 as research samples. The data in this paper are taken from the Wind database. The sample descriptive statistics are shown in Table 2 .

TABLE II. DESCRIPTIVE STATISTICS

\begin{tabular}{|l|l|l|l|l|l|l|}
\hline & Min & Max & Ave. & Std. & Skewness & Kurtosis \\
\hline Asset liability ratio & 16.97 & 74.33 & 50.17 & 14.3 & -0.41 & 0.09 \\
\hline Equity multiplier & 1.2 & 3.9 & 2.18 & 0.68 & 0.89 & 0.25 \\
\hline Current assets ratio & 6.05 & 93.4 & 48.40 & 22.9 & -0.06 & -0.62 \\
\hline Net sales interest rate & -17.51 & 47.4 & 15.33 & 11.8 & 0.04 & 3.06 \\
\hline Return on net assets & -9.33 & 22.83 & 10.60 & 6.26 & -1.12 & 3.52 \\
\hline Inventory turnover & 0.83 & 27.22 & 6.12 & 6.12 & 2.08 & 5.0 \\
\hline $\begin{array}{l}\text { Accounts receivable } \\
\text { turnover rate }\end{array}$ & 0.87 & 12.25 & 3.75 & 3.10 & 1.63 & 1.80 \\
\hline Turnover of current assets & 0.36 & 0.93 & 0.87 & 0.33 & 1.39 & 3.5 \\
\hline Turnover of fixed assets & 0.46 & 172.5 & 17.75 & 34.2 & 4.17 & 18.97 \\
\hline Turnover of total assets & 0.1 & 0.78 & 0.38 & 0.17 & 0.63 & -0.17 \\
\hline Flow rate & 0.29 & 5.55 & 1.49 & 1.04 & 2.66 & 9.43 \\
\hline Speed ratio & 0.28 & 5.14 & 0.25 & 0.98 & 2.81 & 10.15 \\
\hline Property right ratio & 0.2 & 2.9 & 0.18 & 0.68 & 0.9 & 0.26 \\
\hline
\end{tabular}

Based on the above descriptive statistics, the financial indicators selected in this paper are more reasonable. Among the three indicators of capital structure, the average value of asset-liability ratio is 50.1688 , the minimum value is 16.97 , the maximum value is 74.33 ; the minimum value of equity multiplier is 1.20 , the maximum value is 3.90 , the average is 2.1832; the minimum value of current assets ratio is 6.05 , the maximum value is 93.40 , the average is 48.4016 , the overall is relatively stable. The profitability, operating ability and solvency of the sample also show a good level, which meets the requirements of sample selection as a whole.
IV. EMPIRICAL ANALYSIS

The selected samples and indicators are processed by using MATLAB software. The input and output indicators are input into the self-organizing neural network toolbox. The training steps are selected to be 10, 30, 50, 100, 200, 500 and 1000 iterations. The competition layer is $6 * 6=36$. The clustering results are as follows:

TABLE III. CLUSTERING RESUlts

\begin{tabular}{|c|c|c|c|c|c|c|c|c|c|c|c|c|c|c|}
\hline & \multicolumn{14}{|c|}{ Clustering results } \\
\hline 10 & 1 & 1 & 1 & 36 & 2 & 1 & 24 & 36 & 35 & 36 & 35 & 35 & 1 & 2 \\
\hline 30 & 14 & 31 & 19 & 1 & 21 & 28 & 2 & 12 & 10 & 6 & 4 & 5 & 19 & 9 \\
\hline 50 & 20 & 2 & 3 & 25 & 9 & 16 & 33 & 35 & 22 & 34 & 29 & 24 & 3 & 22 \\
\hline 100 & 17 & 6 & 24 & 12 & 24 & 15 & 34 & 32 & 20 & 33 & 27 & 25 & 24 & 36 \\
\hline 200 & 24 & 34 & 22 & 36 & 18 & 21 & 4 & 2 & 8 & 3 & 8 & 7 & 22 & 10 \\
\hline 500 & 17 & 5 & 10 & 24 & 16 & 15 & 36 & 32 & 27 & 33 & 27 & 25 & 10 & 21 \\
\hline 1000 & 2 & 14 & 15 & 1 & 9 & 21 & 12 & 30 & 23 & 24 & 24 & 35 & 9 & 17 \\
\hline & \multicolumn{14}{|c|}{ Clustering results } \\
\hline 10 & 2 & 1 & 3 & 1 & 35 & 36 & 1 & 7 & 1 & 1 & 1 & & & \\
\hline 30 & 17 & 25 & 1 & 31 & 5 & 12 & 25 & 15 & 29 & 31 & 36 & & & \\
\hline 50 & 17 & 19 & 31 & 7 & 24 & 36 & 13 & 21 & 11 & 1 & 6 & & & \\
\hline 100 & 20 & 11 & 29 & 6 & 25 & 31 & 5 & 22 & 13 & 3 & 1 & & & \\
\hline
\end{tabular}




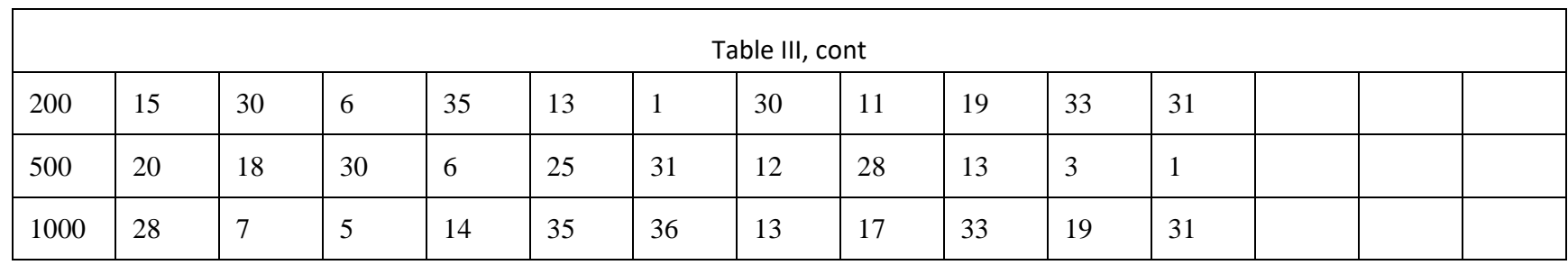

From the clustering results in the above figure, when the number of training steps is 10 steps, the first, second, third, sixth, thirteen, sixteen, eighteen, twenty-first, twenty-third, twenty-fourth and twenty-fifth. These enterprises are divided into one category, namely, Century Star Source, China Tianzhu, Qidi Sander, Bishuiyuan, Guosheng Environmental Protection, Central Environmental Protection, Shanghai Environment, Weiming Environmental Protection, Botian Environment, Luen Thai Environmental Protection and Zhongzhi Shares; divided into the second category is Kaimei Special Gas, Zhongdian Environmental Protection, Mengcao Ecology and Shanghai Washing; the third category is the fresh environment, Boschke, Meishang Ecology; the fourth category is Ke Rong. Environment; divided into the fifth category is Yongqing Environmental Protection, Xingyuan Environment, Mengcao Ecology and De Chong Environmental Protection; divided into the sixth category of high-energy environment; divided into the seventh category is Yuanda Environmental Protection, a total of seven category.

When iterations are 30, 25 listed companies are divided into 20 categories; when iterations are 50, they are divided into 22 categories; when iterations are 100, they are divided into 20 categories; when iterations are 200, they are divided into 22 categories; when iterations are 500, they are divided into 22 categories; when iterations are 1000, they are divided into 20 categories.

As shown in figure 1, figure 1 shows the network topology structure of SOM, figure 2 shows the distance between adjacent neurons, and the competition layer neurons have $6 * 6=36$. In figure 2 , blue represents neurons. The red line represents the direct connection of neurons. The color in each diamond represents the distance between neurons, from yellow to black. The darker the color, the farther the distance between neurons.

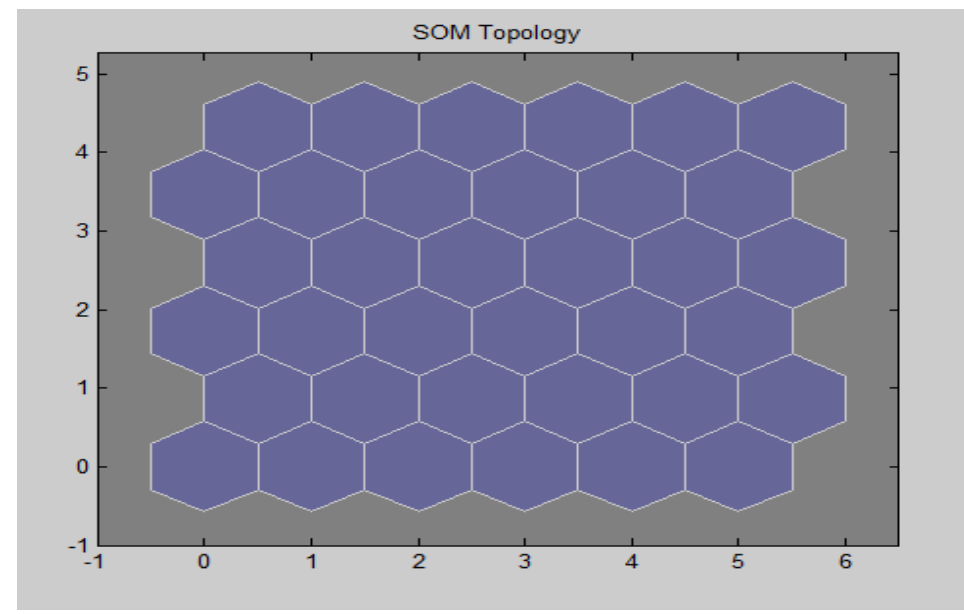

Fig. 1. Topological structure of SOM network topology

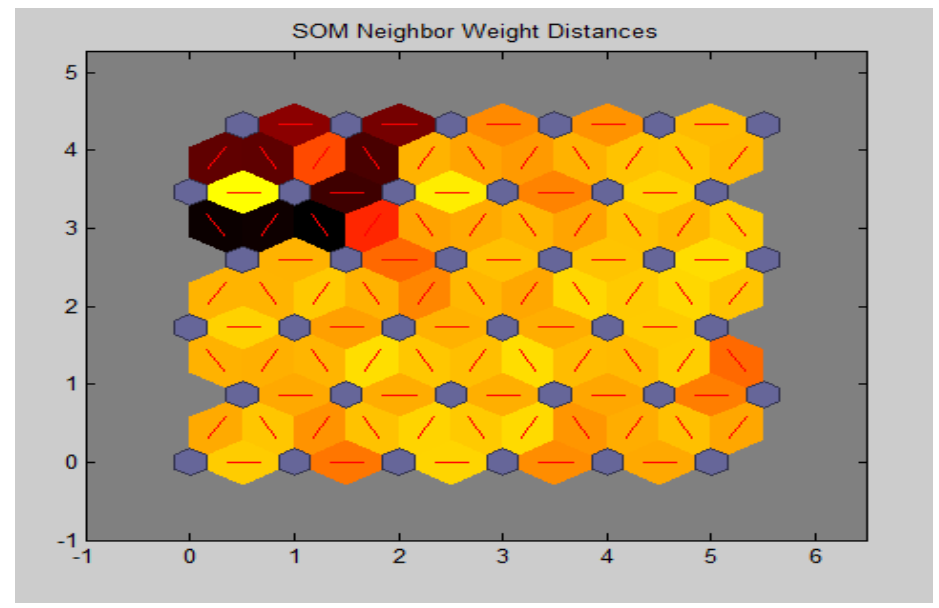

Fig. 2. The distance between adjacent neurons

\section{CONCLUSION}

In this paper, SOM neural network clustering algorithm is used to analyze the financial situation of environmental protection enterprises in Listed Companies in China. By iterating the samples 10, 30, 50, 100, 200, 500 and 1000 times, several different classification results are obtained. Therefore, the financial risk model based on self-organizing neural network clustering algorithm has certain value for investors and managers of environmental protection listed companies. The clustered companies can be classified and analyzed by clustering method, which provides a basis for better studying the financial risk of environmental protection listed companies. At present, China's listed companies are facing tremendous challenges, but also facing more opportunities. Managers should use the SOM neural network model from the perspective of financial risk analysis, for various types of 
financial risk analysis and early warning, in order to prevent financial risk of enterprises:

Firstly, we should establish and improve the relevant legal system, improve the top-level design of financial risk management of listed companies, and effectively protect the interests of small and medium shareholders; relevant departments should form a joint investigation committee to strengthen information disclosure of external guarantees and major related party transactions of listed companies; at the same time, we should prevent large shareholders from taking up too much capital and using each other. The way to transfer company assets fundamentally avoids the company's financial difficulties.

Secondly, we should strengthen the perfection of the internal control system of listed companies, optimize the corporate governance structure, supervise the control rights of companies through strong measures, establish a sandbox mechanism for financial risk supervision, and establish a sound multi-level financial risk early warning system.

Thirdly, establish a good external environment to guard against the financial risks of enterprises, improve the risk awareness of managers, train the managers of enterprises on the knowledge of financial risks, raise awareness, and identify the potential risks of enterprises as soon as possible, and take timely measures to deal with them.

\section{REFERENCES}

[1] Liu Aiqin, Li Yongqing. Construction of Personalized Service recommendation system of University Library based on SOM Neural Network [J/OL]. Library Forum No. 2018,pp 1-9. (In Chinese)

[2] Yang Zhimin, Hua Xiangyu, Ye Yafen, Shao Yuanhai.Financial spatial links and SOM neural network central level recognition-a case study of Zhejiang province county $[\mathrm{J}]$. Economic geography, 2014, 34 (12).pp 93-98. (In Chinese)

[3] Zhang Faming. A dynamic credit evaluation method combining SOM and K-means algorithm and its application [J].Operations Research and Management, 2014, 23 (06).pp 186-192.(In Chinese)

[4] Xu Buyun, Ni He.Comparison and analysis of self-organizing neural network and $\mathrm{K}$-means clustering algorithm[J].New Industrialization, 2014,4(07).pp 63-69. (In Chinese)

[5] Xiong Tao, Bao Yukun, Hu Zhongyi, Zhang Jinlong. Multi-step prediction of the Shanghai-Shenzhen 300 index based on SOM and SVMs [J].Systems Engineering, 2012, 30 (10).pp 36-42. (In Chinese)

[6] Jiaotao. Radial Basis Function Neural Network Optimization and Its Application in Enterprise Financial Early Warning [D]. Xi'an University of Electronic Science and Technology, 2011. (In Chinese) 